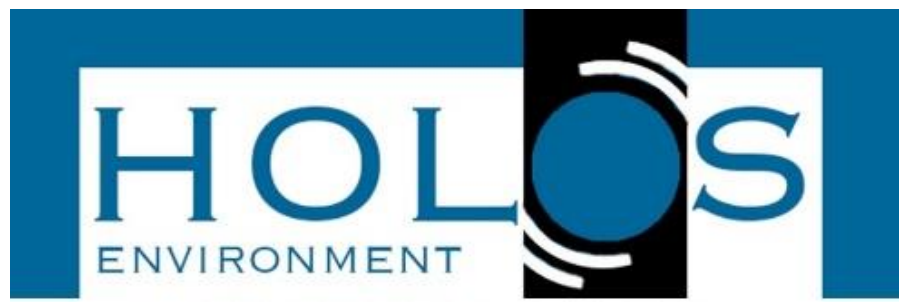

\title{
IDENTIFICAÇÃO DE ÁREAS APTAS A BARRAGINHAS NA BACIA DO RIO SÃO LAMBERTO
}

\section{IDENTIFICATION OF AREAS SUITABLE FOR A DAM IN THE SÃO LAMBERTO RIVER BASIN}

\author{
Victor Rodrigues Aragão'; Ana Clara Soares de Souza²; Thiago Paoliello3; Thiago \\ Gonçalves Silva3; Felipe Aquino Lima²
}

Artigo recebido em: 04/02/2019 e aceito para publicação em: 13/06/2019.

DOI: http://dx.doi.org/10.14295/holos.v19i2.12328

Resumo: As barraginhas são bacias de contenção e infiltração que possuem, principalmente, um caráter conservacionista em relação aos solos, proporcionando a esses, maior irrigação e controle de processos degradativos. Dentro deste contexto e, tendo em vista a importância da bacia do rio São Lamberto para a mesorregião do Norte de Minas Gerais e os problemas ambientais ocorrentes nesta, este trabalho objetivou localizar e evidenciar áreas de aptidão a barraginhas nesta bacia. Para o alcance do objetivo proposto, adotou-se como metodologia a atuação conjunta de um ambiente de Sistema de Informação Geográfica com uma análise multicritério, sendo a base do estudo os critérios ambientais de fluxo acumulado, declividade, cobertura vegetal e proteção do solo, e tipo do solo. Os resultados obtidos de aptidão, nos quais foram agregados às principais estradas rurais e as duas mais importantes nascentes da bacia trabalhada, permitiram compreender facilmente as áreas críticas, na qual $11 \%$ da bacia do rio São Lamberto se encontra sob altíssima aptidão a barraginhas e $18 \%$ sob alta. Com o presente estudo foi possível concluir que, de fato, os critérios ambientais são complexos a ponto de não poderem ser analisados separadamente, como se fazia na era do surgimento das barraginhas no Brasil, tendo a metodologia empregada, uma auxiliadora em tomadas de decisão, não somente ao processo de locação, mas aos dimensionamentos dessas barragens e na adoção de futuras práticas de recuperação de áreas.

Palavras-chave: Bacias de contenção e infiltração. Sistema de Informação Geográfica. Análise multicritério. Aptidão. Práticas de recuperação de áreas.

Abstract: The containment and infiltration dams have, mainly, a conservationist character in relation to the soils, providing to them, greater irrigation and control of degraded processes. Within this context, and in view of the importance of the São Lamberto river basin to the mesoregion of the North of Minas Gerais and the environmental problems occurring in it, this work aimed to locate and to highlight areas of aptitude to nitrates in this basin. In order to reach the proposed objective, a joint geographic information system environment with a multicriteria analysis was adopted as methodology, being the basis of the study the environmental criteria of accumulated flow, declivity, vegetation cover and soil protection, and type of soil. The aptitude results, in which they were added to the main rural roads and the two most important springs of the basin worked, allowed to easily understand the critical areas, in which $11 \%$ of the São Lamberto river basin is under very high capacity for dams and $18 \%$ under high. With the present study it was possible to conclude that, in fact, the environmental criteria are complex to the point that they can not be analyzed separately, as was done in the era of the emergence of nitrates in

\footnotetext{
${ }^{1}$ Instituto Educacional Santo Agostinho (IESA), São Gonçalo do Pará, MG. E-mail: (araaorvictor@gmail.com)

2 Universidade Federal de Minas Gerais (UFMG), Belo Horizonte, MG. E-mails: ana.clara.s.s@outlook.com, felipeaquinolima@bol.com.br)

3 Universidade Estadual de Montes Claros (UNIMONTES), Montes Claros, MG. E-mails: paoliellothiago@gmail.com, thiago.silva@fasa.edu.br,
} 
Brazil, with the methodology employed, not only to the leasing process but also to the dimensioning of these dams and the adoption of future recovery practices.

Keywords: Containment and infiltration basins. Geographic Information System. Multicriteria analysis. Ability. Areas recovery practices.

\section{INTRODUÇÃO}

A busca pela mitigação dos tantos processos degradativos tem sido veemente em todo o mundo, e até as áreas mais distantes das ciências do ambiente discutem o tema. A natureza tem, de fato, ganho atenção especial, em que os poucos ambientes ainda preservados tem sido pontos-chave para a descoberta de processos acelerados de mitigação, mas é notável que há ainda uma distância entre argumentos e ações.

Frente às possibilidades disponíveis de recuperação de áreas estão as barraginhas, caracterizadas por Barros (2011) como sistemas de contenção e infiltração da água de chuva que provém do escoamento superficial, que desde os anos 90 tem sido um dos métodos mais eficientes de caráter conservacionista do solo e de ordem social.

Dentre seus amplos benefícios, a redução dos processos erosivos e o aumento da água no interior do solo são os resultados mais esperados pelas ciências do ambiente. Nestes pontos, Pacheco (2016) argumenta que o sistema de barraginhas é uma metodologia que ao longo do tempo se tornou altamente difundida no Brasil, mas que até então se apresenta pouco aprofundada, desde a escolha de áreas aptas a um padrão de dimensionamento, fatores estes que são essenciais para buscar a máxima eficiência do sistema.

De uma maneira geral, essas barragens são escavações no solo que podem apresentar diferentes formatos e dimensões, e esses valores podem variar de acordo com a metodologia adotada e o local a que se trabalha. Esses sistemas podem se apresentar dispersos ao longo de um terreno ou linearmente num trecho, por exemplo, em estradas rurais, sendo esses os dois padrões mais utilizados no Brasil (BARROS, 2011).

Para que haja uma tomada de decisão quanto à locação e dimensionamento desse tipo de sistema é necessário compreender o ambiente a que se tem disponível, suas formas e peculiaridades. Inequivocamente, o mesmo, sendo natural ou antropizado, dita suas necessidades e suas aptidões. E uma das alternativas eficazes está na utilização de ferramentas de Sistemas de Informações Geográficas - SIG. Esses 
se resumem em equipamentos e meios tecnológicos voltados à análise, gestão e compreensão dos diferentes espaços e fenômenos que nele acontecem (CAVALCANTE, 2015).

Ressaltam Santos, Louzada e Eugênio (2010) que esta alternativa, no entanto, deve ser aliada a uma análise multicriterial, haja vista que uma pesquisa desta natureza envolve o alcance de uma resposta objetiva frente a critérios ambientais que se inter-relacionam, e essa correspondência, em sua essência, é demasiadamente complexa. A se incluir o fato de que as ferramentas SIG precisam realizar processos de classificação e reclassificação, a fim de atender a uma equação geral, reforçando mais uma vez a necessidade de uma avaliação multicritério.

E por fim, evidenciam Versiani Júnior, Nuzzi e Fróes (2007) que as estradas rurais são elementos essenciais num estudo de aptidão a barraginhas, compreendendo canais de escoamento ao leito dos cursos d'água. Neste contexto, este trabalho objetivou localizar e evidenciar áreas aptas a barraginhas na bacia do rio São Lamberto utilizando uma metodologia que alia um ambiente SIG a uma análise multicriterial, tendo como base os critérios ambientais de fluxo acumulado, declividade, cobertura vegetal e proteção do solo, e tipo de solo. Visando, assim, estruturá-los e combiná-los mediante suas variáveis, a fim de se obter um resultado pontual, não subjetivo e fundamentado a tomadas de decisão.

\section{MATERIAL E MÉTODOS}

A bacia do rio São Lamberto é uma sub-bacia do rio Jequitaí e micro-bacia do rio São Francisco, na qual abrange as áreas municipais de Montes Claros, Claro dos Poções e Jequitaí, sendo a maior parte $(51 \%)$ de sua área inserida no município montesclarense (Figura 1). 
Figura 1 - Bacia do rio São Lamberto e suas configurações de localização e dimensão

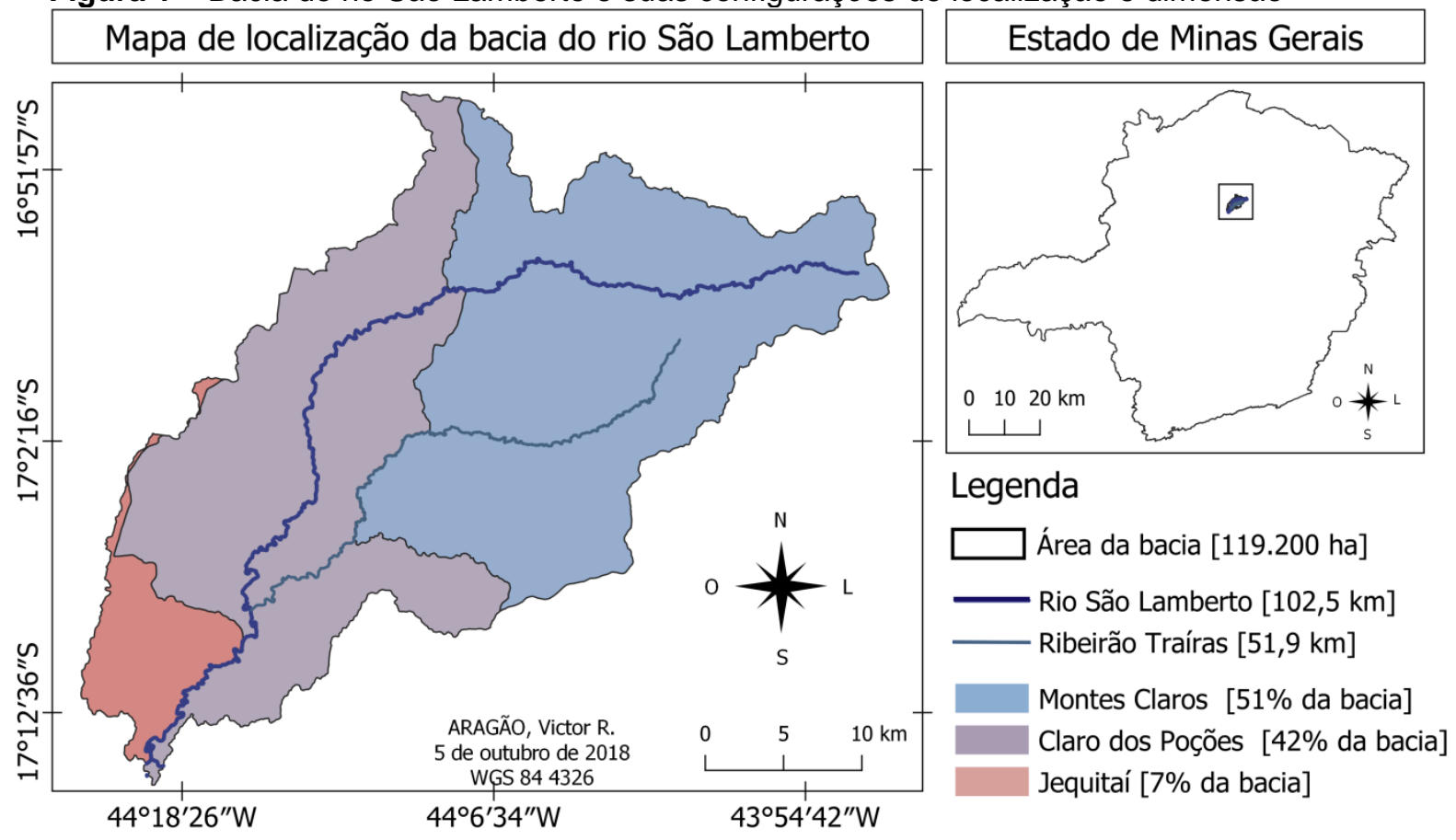

Fonte: Próprio autor

O rio São Lamberto detém vasta drenagem, com uma extensão total de 102,5 km, como evidencia a Figura 1, e possui o ribeirão Traíras como seu grande tributário, afluente esse que ganha destaque por auxiliar em seu amplo volume, como evidenciam Durães et al. (2017).

A bacia está inclusa no clima tropical com estação seca de inverno $(A w)$, mediante classificação de Köppen, aduzindo uma taxa de precipitação média de 1.000 mm.ano-1 ${ }^{-1}$ tendo estação chuvosa com altas temperaturas, úmida e de céu encoberto. Já a estação seca revela temperaturas mais brandas e céu geralmente limpo. A temperatura média anual é de $23^{\circ} \mathrm{C}$ (NUNES et al., 2005).

Os solos da bacia, como evidenciam Nunes et al. (2005) e Durães et al. (2017) possuem distrofias, caracterizando-se por solos de baixa fertilidade e alta capacidade de erosão, sendo em sua maioria rasos. O predominante, segundo a Embrapa (2006), o Latossolo Vermelho-Amarelo Distrófico (LVAd) alterna-se com o Cambissolo Háplico Tb Distrófico (CXd), Neossolo Litólico RL Distrófico (RLd) e Latossolo Vermelho Distrófico $(L V d)$, onde a nascente do São Lamberto se encontra em Cambissolo Háplico Tb Distrófico e a do ribeirão Traíras em Latossolo Vermelho-Amarelo Distrófico.

A vegetação ocorrente na bacia do rio São Lamberto é típica do cerrado, alternando-se entre arbustiva-herbácea, arbustiva-arbórea e zona de tensão ecológica, 
como evidenciam Nunes et al. (2005) e Durães et al. (2017). Este tipo de área é definida pelo IBGE (2012) como sendo de variação, e que costumeiramente detém mais de 2 tipos de formações vegetais, com ou sem pressão antrópica.

Para o estabelecimento dos critérios ambientais neste trabalho, seguiu-se as recomendações dos estudos de Santos, Louzada e Eugênio (2010), Pinto et al. (2015) e Pacheco (2016), nos quais subsidiaram e fundamentaram a base desta pesquisa, sendo: fluxo acumulado, declividade, cobertura vegetal e proteção do solo, e tipo de solo. Desta forma, foi possível não somente evidenciar o caminho preferencial das águas, mas também as influências de velocidade de escoamento por meio das formas do relevo, as áreas com vegetação e de solo descoberto.

Para tanto, a metodologia adotada para a seleção de áreas aptas a barraginhas se baseou na utilização do QGis 3.2 Bonn aliada a uma análise multicritério, com fundamentação primária nos estudos de Santos, Louzada e Eugênio (2010), Pinto et al. (2015) e Pacheco (2016), com apoio secundário nas pesquisas de Ghezzi (2003), Pachechenik (2004), Miara e Oka-Fiori (2007) e Ribeiro (2014).

No QGis, realizou-se a classificação de fluxo acumulado e declividade por meio do Modelo Digital de Elevação Hidrologicamente Consistente (MDEHC) obtido no Serviço Geológico dos Estados Unidos (USGS), bem como a delimitação da bacia e rede de drenagem, com as ferramentas r.fill, r.watershed e r.wateroutlet. Com o uso de uma imagem do satélite LANDSAT-8, sob código L8-OLI 227/064, datada de 22 de agosto de 2018, sob às 13h48min30seg, do sensor: OLI, com \% em nuvens de 2,79 e qualidade de imagem 9, em órbita circular, ordenou-se as variáveis de cobertura vegetal e proteção do solo, através da ferramenta Semi-Automatic Classification Plugin (SCP), como revela Pacheco (2016).

Posterior à classificação, como determinam os autores supracitados, reclassificou-se os critérios "substituindo" suas variáveis por valores entre 0 e 10, a fim de se criar um padrão válido aceitável à equação de aptidão. Então, por meio da ferramenta Reclassify by table e a Tabela 1 , realizou-se o procedimento. 
Tabela 1 - Grau de aptidão e notas para reclassificação

\begin{tabular}{ll|l}
\hline Aptidão & Notas & \multicolumn{2}{l}{ Grau } \\
\hline Menos Apto & 0 & Menos Apto \\
Mais Apto & 10 & Mais Apto
\end{tabular}

Fonte: Adaptado de Santos, Louzada e Eugênio (2010), Pinto et al. (2015) e Pacheco (2016)

Passou-se então à Análise Multicritério. Neste processo, que é baseado no Método de Análise Hierárquica, desenvolve-se uma hierarquia mediante valores de julgamento. Assim, os critérios ambientais são comparados entre si, recebem um valor correspondente ao par, originando uma matriz pareada.

Nesta fase, como evidenciam Ghezzi (2003), Pachechenik (2004), Santos, Louzada e Eugênio (2010), e Pacheco (2016), os graus de julgamento podem obedecer de 1 a 3 fatores, podendo variar de pesquisador a pesquisador, sendo portanto: 1) A comparação de um critério ambiental a outro segue a experiência do indivíduo da pesquisa; 2) Através de investigação de bibliografias, o pesquisador ratifica sua escolha; 3) In loco, grupo multidisciplinar discute e estabelece os julgamentos.

Diferentemente de Pacheco (2016) e obedecendo unicamente ao fator 2, ao invés de se aplicar manualmente os valores de julgamento numa matriz pareada, esses foram inseridos no sistema computacional IPÊ 1.0, como Santos, Louzada e Eugênio (2010) evidenciam esta possibilidade. O sistema adotado então realiza uma matriz pareada por algoritmos, permitindo ao fim da operação obter os pesos estatísticos $P w, P x, P y$ e $P z$, utilizados na Equação 1. Onde $F=$ fluxo acumulado, $D=$ declividade, $\mathrm{C}=$ cobertura vegetal e proteção do solo, e $\mathrm{T}=$ tipo de solo.

$$
A p t=(\mathrm{Pw} * \mathrm{~F})+(\mathrm{Px} * \mathrm{D})+(\mathrm{Py} * \mathrm{C})+(\mathrm{Pz} * \mathrm{~T})
$$

Junto aos pesos, um valor chamado Razão de Consistência $(R C)$ é gerado ao final do processo do sistema computacional citado. O RC aponta se os pesos adotados são satisfatórios, e para tanto, o mesmo deverá se apresentar menor que 0,10 (SANTOS, LOUZADA E EUGÊNIO, 2010). Posterior à inserção da equação de aptidão na calculadora raster, realizou-se o mapeamento das estradas rurais mais importantes e críticas da bacia do rio São Lamberto, atendendo à recomendação de Versiani Júnior, Nuzzi e Fróes (2007). 


\section{RESULTADOS E DISCUSSÃO}

O fluxo acumulado, sob unidade de pixels de contribuição, que segundo Mendes e Cirilo (2001) expressa comportamentos da rede hidrográfica a que se trabalha, evidencia áreas preferenciais de acúmulos de água provenientes de escoamentos superficiais.

Neste trabalho, a classificação deste critério ocorreu por meio da confecção de um mapa com 4 classes diferentes, variando em tons de azul para 1 único tom rosado, sendo esta variável com cor diferenciada, a que aduz regiões de maiores fluxos acumulados na bacia do rio São Lamberto.

Os resultados obtidos evidenciam um comportamento heterogêneo na bacia do rio São Lamberto quanto a este critério, onde as cores que tendem ao azul claro revelam representações de nenhum ou poucos pixels de contribuição, sendo, portanto, porções da bacia consideradas divisores de água, como revela a Figura 2.

Figura 2 - Mapa relativo ao fluxo acumulado da bacia do rio São Lamberto

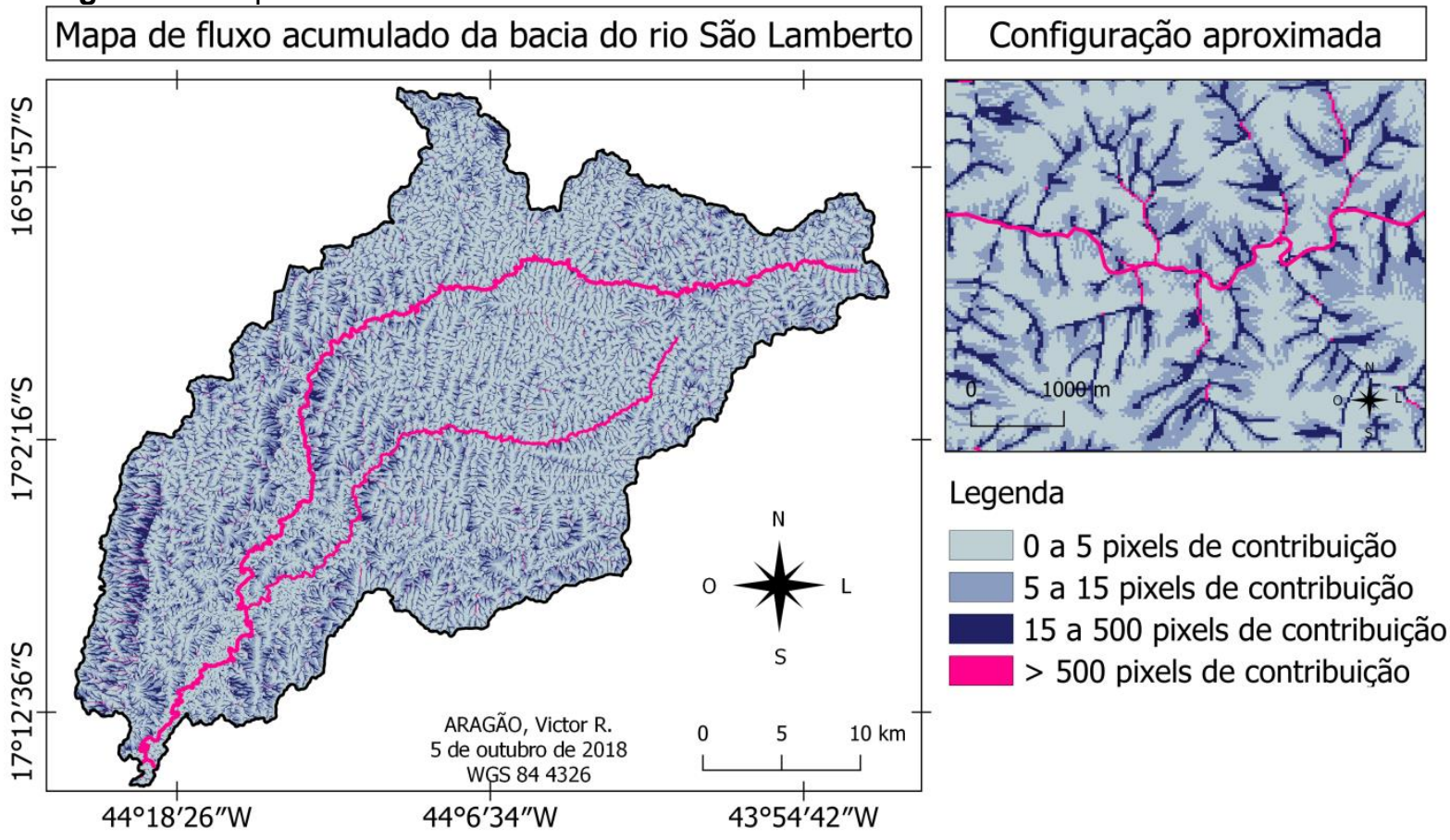

Fonte: Próprio autor

Para a reclassificação então, quanto mais pixels de contribuição, mais alta a nota atribuída à variável, com a exceção da variável que detém fluxos acima de 500 pixels, recebendo nota 0, como recomenda Pacheco (2016) na Tabela 2. 
Tabela 2 - Resultados obtidos de fluxo acumulado quanto à reclassificação.

\begin{tabular}{lcc}
\hline & Nota de reclassificação & Análise isolada \\
\hline $0-5$ pixels & 1 & Divisores topográficos \\
$5-15$ pixels & 5 & Moderadamente indicadas a barraginhas \\
$15-500$ pixels & 10 & Áreas muito indicadas a barraginhas \\
$>500$ pixels & 0 & Maior concentração de escoamento
\end{tabular}

Fonte: Adaptado de Pacheco (2016)

O segundo critério analisado neste trabalho foi a declividade, na qual apresenta uma ligação direta com a energia cinética dos escoamentos superficiais, como evidencia Ghezzi (2003), onde maiores declives geram maiores velocidades para os escoamentos e para tanto, maior taxa de erosão (MIARA e OKA-FIORI, 2007). Assim, a declividade pode influenciar no valor de implantação de uma barraginha, bem como afetar sua estrutura e funcionamento. Segundo o autor, recomenda-se barraginhas até uma declividade máxima de $20 \%$, e para tanto, este trabalho adaptou a última variável deste critério ambiental, como mostra a Figura 3 (BERTONI E LOMBARDI NETO, 2005).

Figura 3 - Mapa de declividade da bacia do rio São Lamberto

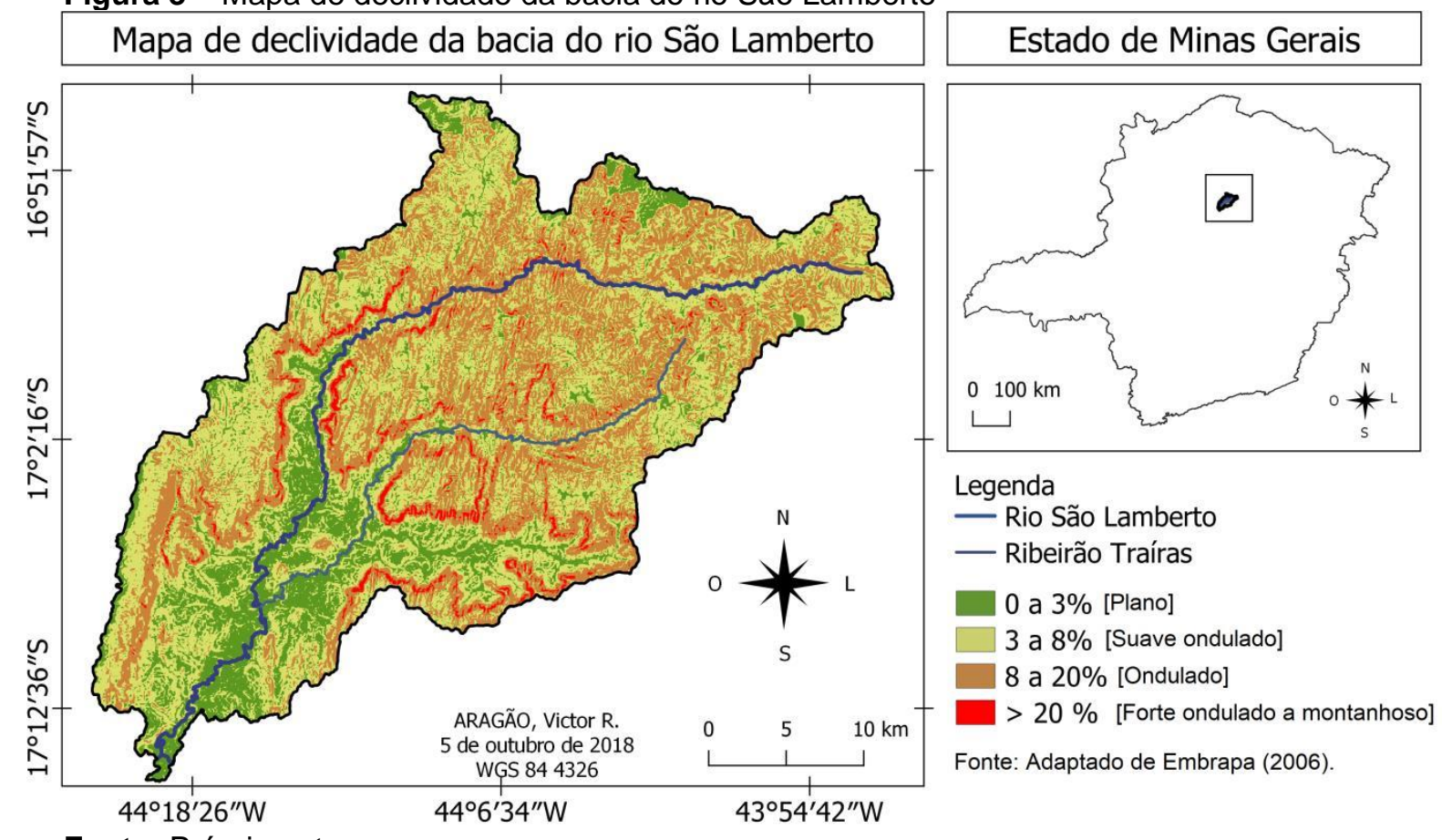

Fonte: Próprio autor

Os resultados obtidos quanto à declividade também refletem num comportamento heterogêneo na bacia do rio São Lamberto. O rio, que nasce a leste, percorre 
declividades mais altas próximas à nascente, num terreno de suave ondulado a ondulado, e nas áreas de proximidade à foz, observa-se terrenos mais planos.

A reclassificação desse critério seguiu também as recomendações de Santos, Louzada e Eugênio (2010) e Pacheco (2016), autores que também argumentam o fato de que maiores declives acarretam em maiores velocidades de escoamentos superficiais, indo ao encontro dos argumentos de Ghezzi (2003), Pachechenik (2004), Bertoni e Lombardi Neto (2005).

Os resultados de reclassificação desse critério também foram agregados à Tabela 3 com o objetivo de uma melhor compreensão.

Tabela 3 - Resultados obtidos de declividade quanto à classificação e reclassificação

\begin{tabular}{lcc} 
& Nota de reclassificação & Análise isolada \\
\hline $0-3 \%$ & 1 & Áreas não indicadas a barraginhas \\
$3-8 \%$ & 5 & Moderadamente indicadas a barraginhas \\
$8-20 \%$ & 10 & Áreas muito indicadas a barraginhas \\
$>20 \%$ & 0 & Áreas não indicadas a barraginhas
\end{tabular}

Fonte: Adaptado de Pacheco (2016)

Seguindo os padrões de Durães et al. (2017), estudo também ocorrido na bacia do São Lamberto, o critério relativo à cobertura vegetal e proteção do solo foi padronizado entre as variáveis de vegetação densa, vegetação esparsa/rala e solo exposto/urbanização.

Os resultados obtidos evidenciam que a vegetação esparsa/rala é predominante na bacia do rio São Lamberto, seguida da vegetação densa e em sequência a variável mais crítica deste critério, os solos expostos/urbanização, nos quais se apresentaram em 10\% em relação à área total da bacia, como revela a Figura 4. 
Figura 4 - Mapa de cobertura vegetal e proteção do solo

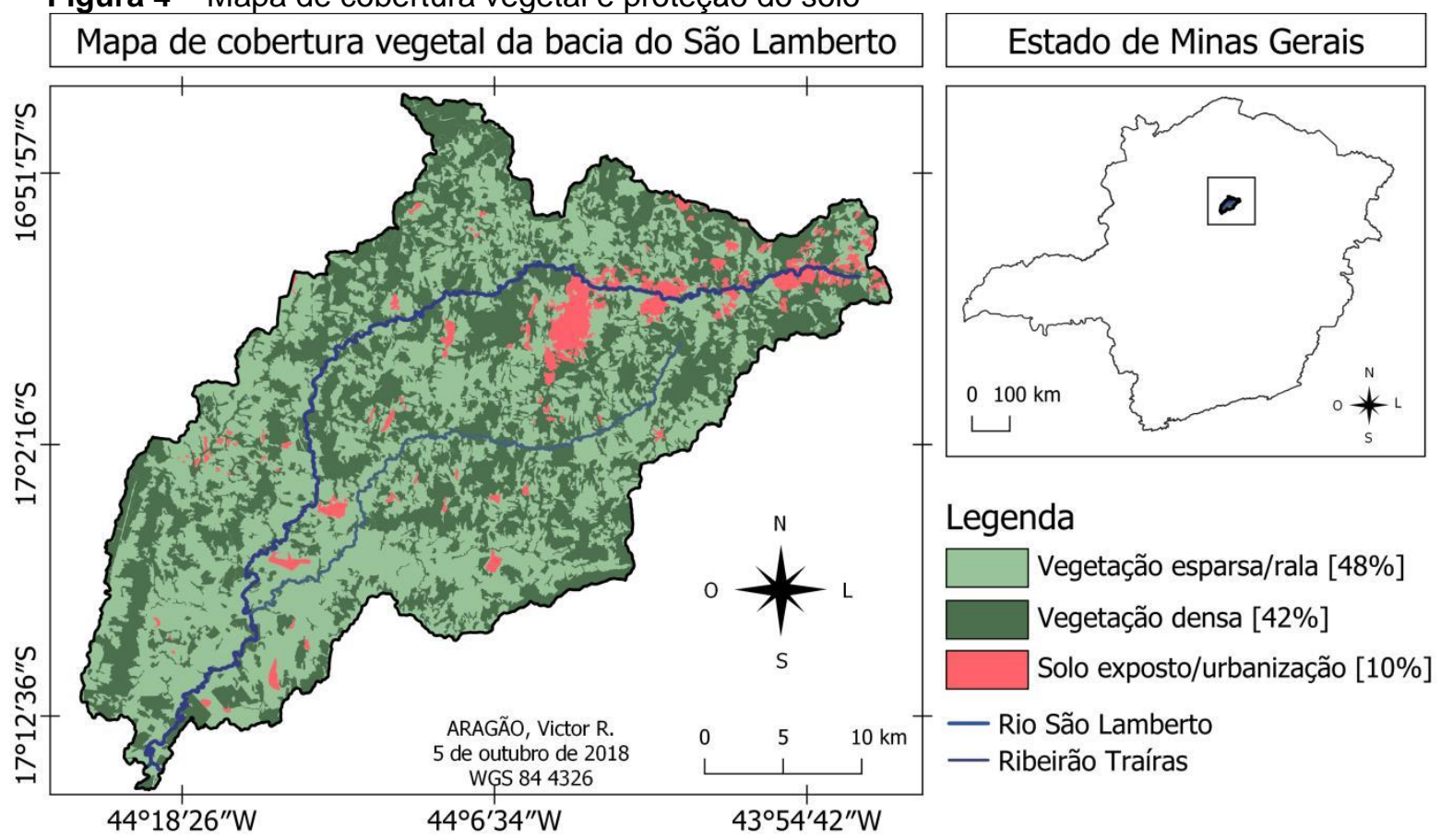

Fonte: Próprio autor

Nota-se que as áreas críticas de solos expostos/urbanização se concentram mais próximas à nascente do rio São Lamberto, a leste. Fato que já era evidenciado por Versiani Júnior, Nuzzi e Fróes (2007), explicado pelas atividades degradadoras, como areeiras, além de empresas e comunidades na região. À medida que se percorre o rio em direção à foz, a sudoeste, a bacia tende a uma diminuição dos solos expostos. Os resultados de reclassificação quanto à cobertura vegetal e proteção do solo foram agregados à Tabela 4.

Tabela 4 - Resultados obtidos de cobertura vegetal e proteção do solo

Nota

\begin{tabular}{lcc}
\hline Solo exposto/urbanização & 10 & Áreas muito indicadas a barraginhas \\
Veg. esparsa/rala & 8 & Áreas muito indicadas a barraginhas \\
Vegetação densa & 4 & Pouco indicadas a barraginhas
\end{tabular}

Fonte: Adaptado de Pinto et al. (2015)

O solo predominante na bacia do rio São Lamberto é o Latossolo VermelhoAmarelo Distrófico (LVAd), com variações de Cambissolo Háplico Tb Distrófico (CXd), Neossolo Litólico RL Distrófico (RLd) e Latossolo Vermelho Distrófico (LVd) (EMBRAPA, 2006), onde a nascente do São Lamberto se encontra em Cambissolo 
Háplico Tb Distrófico e a do ribeirão Traíras em Latossolo Vermelho-Amarelo Distrófico, como evidencia a Figura 5.

Figura 5 - Carta de solos que compõem a bacia do rio São Lamberto

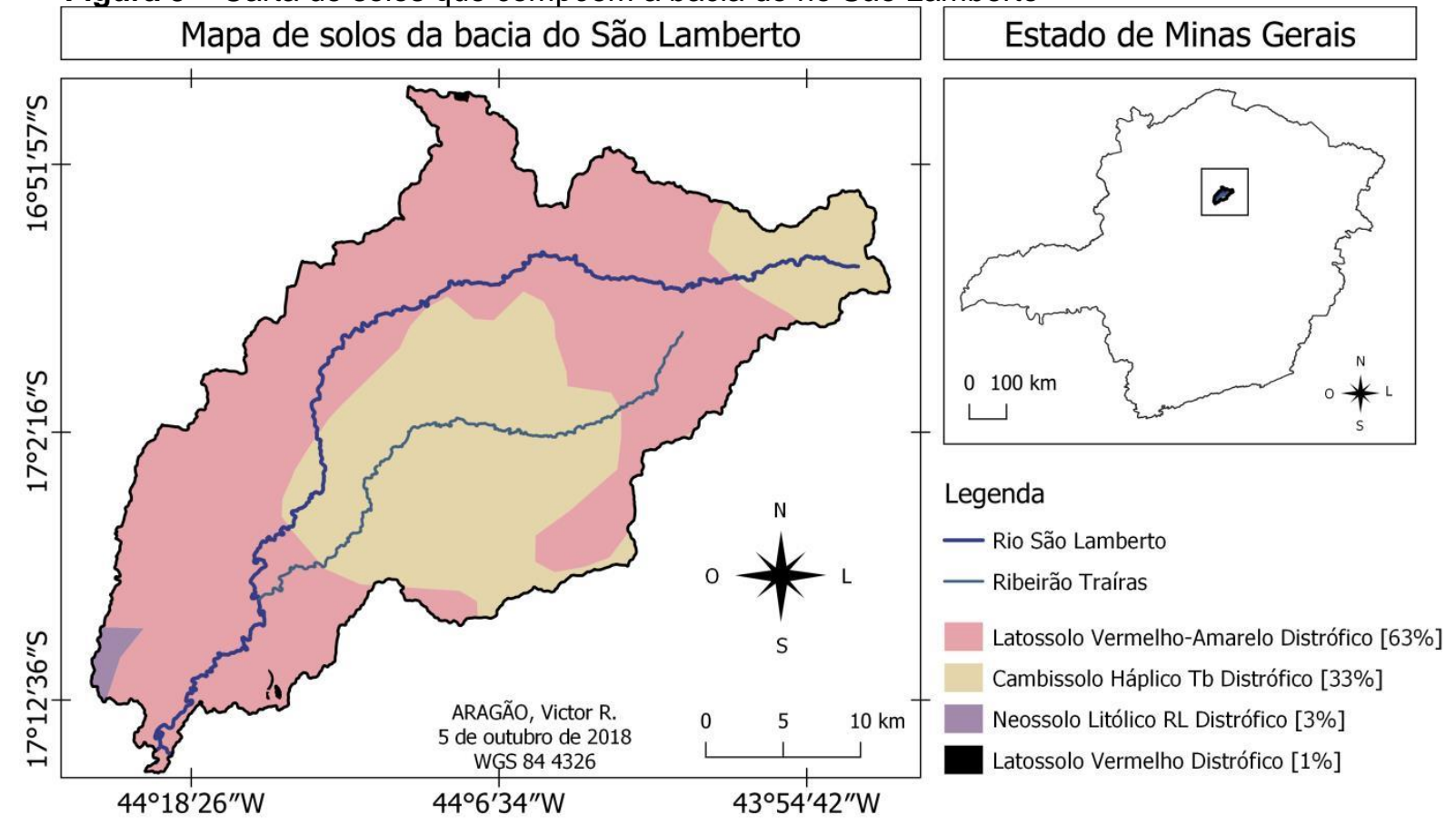

Fonte: Adaptado de EMBRAPA (2006)

Evidenciou-se que $36 \%$ de solos (CXd + RLd) da bacia é muito indicada ao sistema de barraginhas, enquanto que $64 \%$ são pouco indicados (SANTOS, LOUZADA E EUGÊNIO, 2010), mesmo os 4 tipos de solos se apresentando com distrofias.

Tabela 5 - Resultados obtidos de tipos de solo quanto à classificação e reclassificação

\section{Nota de reclassificação}

\begin{tabular}{lcl}
\hline $\mathrm{CXd}$ & 10 & Áreas muito indicadas a barraginhas \\
$\mathrm{RLd}$ & 8 & Áreas muito indicadas a barraginhas \\
$\mathrm{LVd}$ & 4 & Áreas pouco indicadas a barraginhas \\
$\mathrm{LVAd}$ & 4 & Áreas pouco indicadas à barraginhas
\end{tabular}

Fonte: Adaptado de Ghezzi (2003), Pachechenik (2004) e, Santos, Louzada e Eugênio (2010)

Para o alcance do objetivo desta pesquisa, o sistema computacional IPÊ 1.0 foi utilizado na geração e cálculo da matriz pareada, assim como descrito na metodologia desta pesquisa. $O$ procedimento e os resultados foram organizados na Figura 6. 
Figura 6 - Resultados obtidos mediante aplicação do AHP

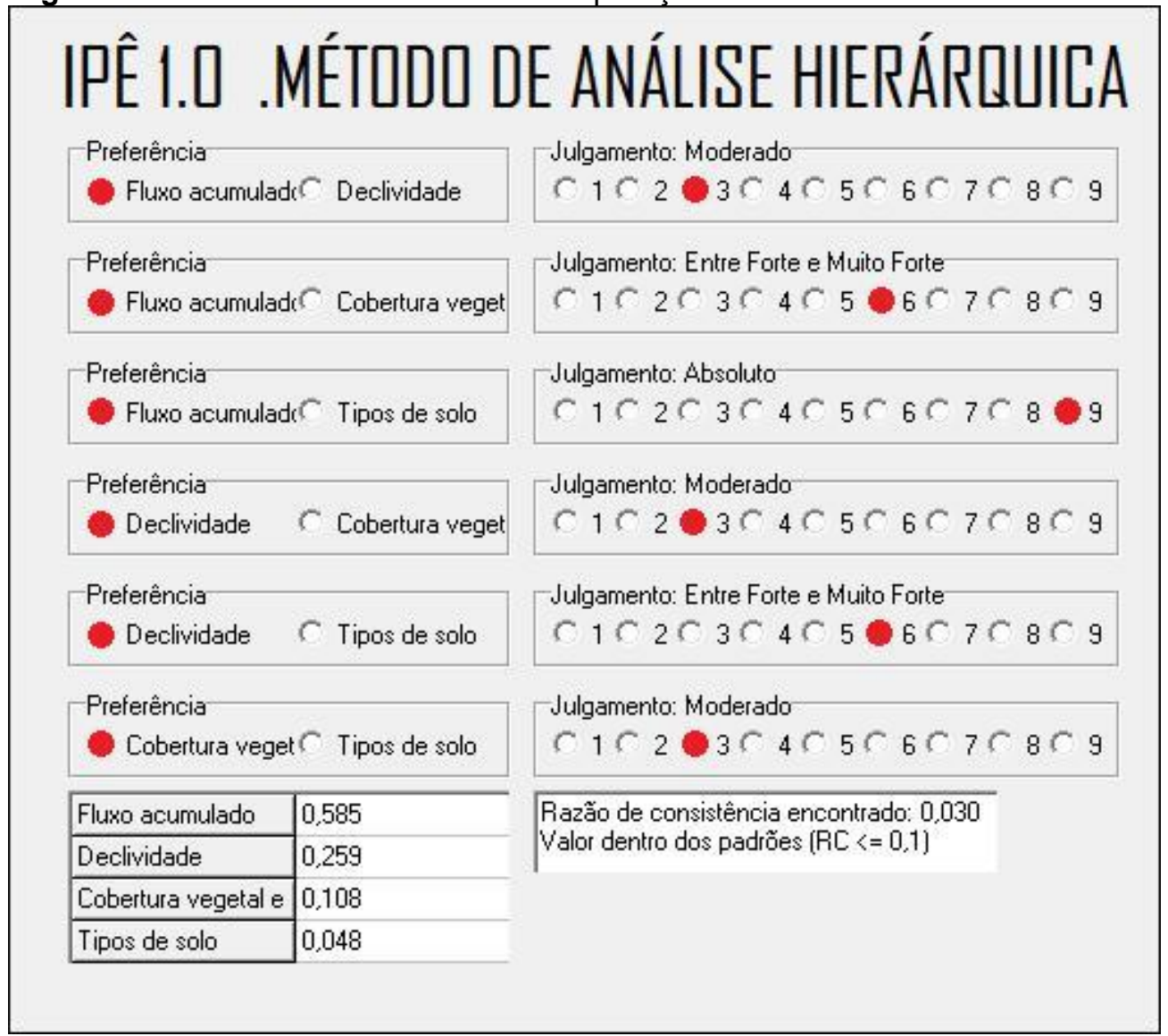

Fonte: Próprio autor

O resultado obtido de Razão de Consistência $(R C)$ está dentro padrão $(<0,10)$ e, portanto, evidencia dados satisfatórios, com confiabilidade, estando esta razão muito próxima da obtida por Pacheco (2016), que foi de 0,033 , mesmo que o presente trabalho tenha sofrido adaptações a fim de se buscar a inclusão da vegetação na análise.

Pinto et al. (2015) reforçam que a cobertura vegetal tende a diminuir processos degradativos, permeabilizando e fornecendo porosidade aos solos, além de colaborar para que a água se infiltre, uma vez que permite a melhor difusão dos fluxos. Um critério necessário ao à locação de barraginhas. Desta forma, a operação de aptidão inserida na calculadora raster do QGis 3.2 seguiu-se por meio da Equação 2.

$$
A p t=(0,585 * \mathrm{~F})+(0,259 * \mathrm{D})+(0,108 * \mathrm{C})+(0,048 * \mathrm{~T})
$$

Através dos resultados obtidos neste trabalho é possível compreender que as áreas mais aptas às barraginhas detêm elevada influência sob as variáveis: 15 a 500 pixels de contribuição quanto ao fluxo acumulado, 8 a 20\% referente à declividade, 
solo exposto no critério de cobertura vegetal e proteção do solo, e cambissolo háplico mediante tipo de solo, como evidenciam Santos, Louzada e Eugênio (2010) e Pacheco (2016).

Mencionadas na introdução deste trabalho, as barraginhas são sistemas que podem se apresentar dispersos ao longo de um terreno ou linearmente num trecho, por exemplo, em estradas rurais. Portanto, a fim de se agregar ainda mais critério à identificação de áreas aptas na bacia do rio São Lamberto, foram mapeadas as principais e mais críticas estradas rurais da área de estudo.

Assim, o grau de aptidão que vai ao encontro das estradas rurais na bacia são ainda mais indicados à implantação do sistema, tendo em vista que Versiani Júnior, Nuzzi e Fróes (2007) avaliam fortemente as vias rurais como também regiões frágeis e vulneráveis, podendo ser consideradas zonas de solos expostos, compreendendo canais de escoamento ao leito dos cursos d'água.

Os resultados apontaram que a leste da bacia, nas proximidades da principal nascente do São Lamberto, há zonas críticas de aptidão, tanto sob alta aptidão (18\%), quanto altíssima aptidão (11\%), tendendo a tons de cores quentes. Com tons de cores frias (branco e cinza), evidenciou-se as áreas com menores aptidões a barraginhas.

A aptidão obtida por meio da metodologia adotada revela a quem implanta o sistema, a possibilidade de riqueza de detalhes e dados precisos quanto ao comportamento do ambiente, uma vez utilizada uma razão de consistência a testar os resultados calculados, fato que tende a levar as barragens de contenção e infiltração à eficiência ótima.

Quanto ao sistema computacional IPÊ 1.0, o mesmo revelou ser uma ferramenta de fácil manuseio e, através deste trabalho, mostrou-se capaz de reduzir consideravelmente o tempo de resolução de cálculos, operações que em muitos casos interrompem a evolução da pesquisa. 
Figura 7 - Carta de aptidão a barraginhas na bacia do rio São Lamberto

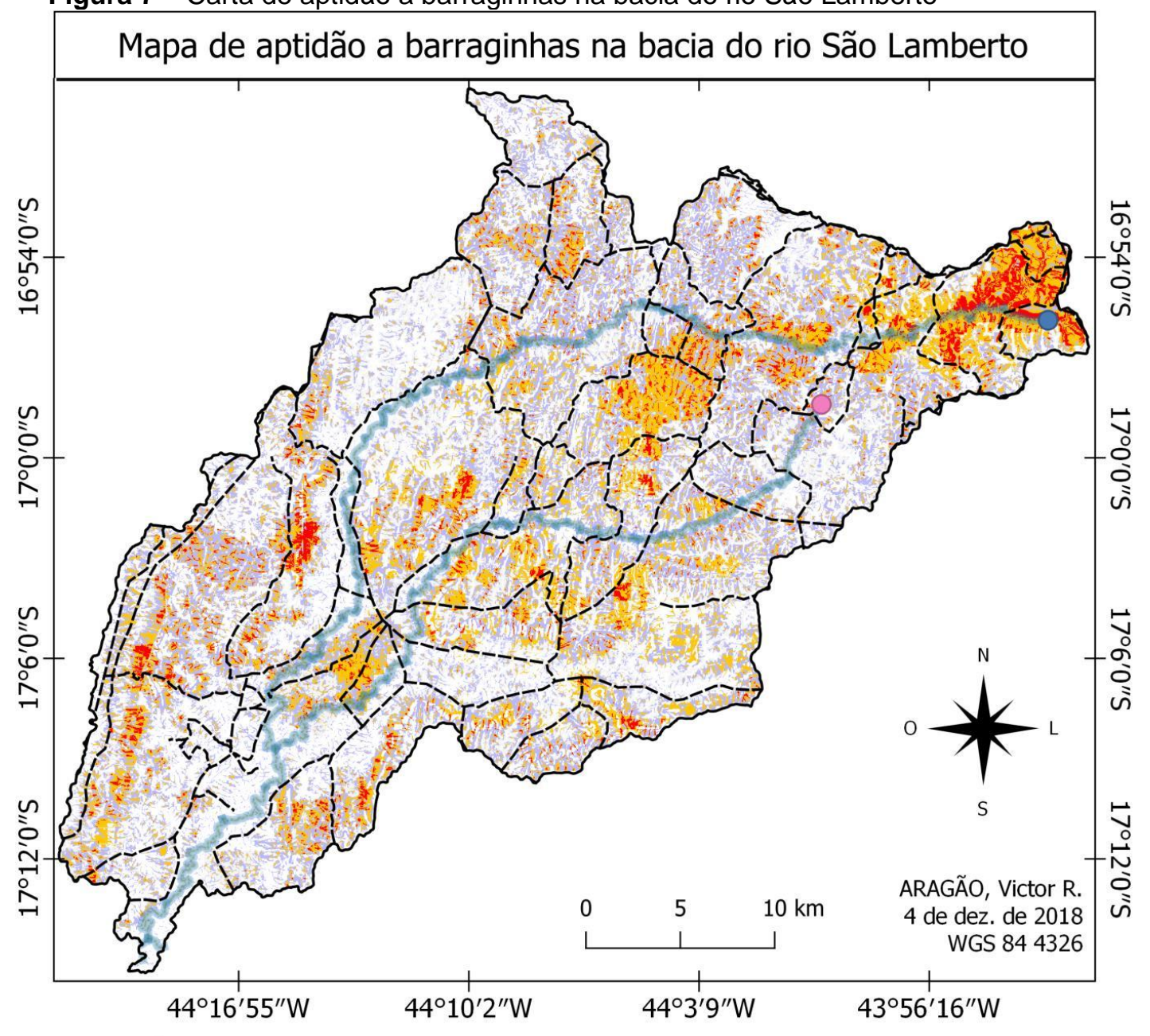

Legenda

----- Estradas rurais

Hidrografia princip

- Nascente do rio São Lamberto

- Nascente do Ribeirão Traíras

Fonte: Próprio autor
Baixa aptidão [38\% da bacia] Média aptidão [33\% da bacia] Alta aptidão [18\% da bacia] Altíssima aptidão [11\% da bacia]

\section{CONCLUSÃO}

Ao fim deste estudo foi possível compreender que a aptidão calculada preserva, de fato, as origens conceituais e teorias de quase 3 décadas desde o surgimento das barraginhas no Brasil, principalmente quanto ao fluxo acumulado, declividade e a forma como os solos estão dispostos no ambiente trabalhado. No entanto, o principal critério ambiental a esses tipos de barragens, no qual evidencia os caminhos preferencias dos fluxos d'água, é demasiadamente complexo para ser compreendido somente in loco, como ainda costuma ser feito. 
Os resultados obtidos revelam que a bacia do rio São Lamberto está em condição crítica, uma vez havendo máxima aptidão a barraginhas nas proximidades da principal nascente que alimenta o rio, podendo estar acarretando não somente pontos de assoreamento, mas sérios processos erosivos, nos quais se apresentam com intensidade na área estudada.

Manifestamente, a metodologia empregada não somente ajuda na tomada de decisão quanto à locação de barraginhas, como também permite uniformizar esta prática, sendo possível sua aplicação em grandes áreas, como foi no caso desta pesquisa, além de possuir sólida fundamentação à parte subsequente de um projeto de barragens de contenção e infiltração, que é o dimensionamento.

O padrão metodológico adotado tem a capacidade de reduzir riscos de uma locação sem uma referência de confiança, uma vez que a Análise Multicritério, que é fundamentada pelo Método de Análise Hierárquica, testa a robustez do sistema por meio de uma Razão de Consistência. Assim, torna-se uma possibilidade de identificação de áreas relativas a outros processos de controle, como de terraceamentos, curvas de nível e platores.

E como prática habitual que jamais pode ser posta de lado, análises quanto a viabilidades de acesso às áreas aptas devem ser levadas em consideração, e para tanto, o modelo desta pesquisa não é um sistema fechado, mas uma possibilidade para que aprimoramentos sejam testados e agregados, a buscar máximas eficiências, uma vez que os ambientes se diferenciam sob inúmeros aspectos.

\section{REFERÊNCIAS}

BARROS, L. C. et al. Integração das tecnologias sociais barraginhas e lago de múltiplo uso. Revista Brasileira de Agropecuária Sustentável, Sete Lagoas, v.1, n.1, p. 1-5, julho de 2011.

BERTONI, J; LOMBARDI NETO, F. Conservação do solo. São Paulo: Ícone, 355p. 2005.

CAVALCANTE, R. Introdução ao SIG. Belo Horizonte: Universidade Federal de Minas Gerais, 2015. $38 \mathrm{p}$.

DURÃES, M. C. O. et al. Caracterização dos impactos ambientais da mineração na bacia hidrográfica do rio São Lamberto, Montes Claros/MG. Caderno de Ciências Agrárias, Montes Claros, v.9, n.1, p. 49-61, julho de 2017.

EMBRAPA - Empresa Brasileira de Pesquisa Agropecuária. Sistema Brasileiro de Classificação de Solos. 2. ed. Rio de Janeiro: EMBRAPA-SPI, 2006. 306 p. 
GHEZZI, A. O. Avaliação e mapeamento da fragilidade ambiental da bacia do rio Xaxim, Baia de Antonina - PR, com o auxílio de geoprocessamento. 2003. 57 f. Dissertação (Mestrado) - Curso de Pós-graduação em Ciências do Solo, Departamento de Solos e Engenharia Agrícola, Universidade Federal do Paraná, Curitiba, 2003.

IBGE - INSTITUTO BRASILEIRO DE GEOGRAFIA E ESTATÍSTICA. Manual técnico da vegetação brasileira: sistema fitogeográfico, inventário das formações florestais e campestres, técnicas e manejo de coleções botânicas, procedimentos para mapeamentos. Rio de janeiro: IBGE- Diretoria de Geociências, 2012. 271p.

MENDES, C. A. B.; CIRILO, J. A. Geoprocessamento em recursos hídricos: princípios, integração e aplicação. Porto Alegre: ABRH, 2001. 536p.

MIARA, M. A.; OKA-FIORI, C. Análise por múltiplos critérios para a definição de níveis de fragilidade ambiental - Um Estudo de Caso: Bacia Hidrográfica do rio Cará-Cará, Ponta Grossa/PR. Revista Ra'e Ga, Curitiba, v. 1, n. 13, p.85-98, 2007.

NUNES, Y. R. F. et al. Atividades fenológicas de Guazuma ulmifolia Lam. (Malvaceae) em uma Floresta Estacional Decidual no norte de Minas Gerais. Lundiana, v. 6, n. 2, p. 99-105, 2005.

PACHECHENIK, P. E. Caracterização hidrológica e da fragilidade ambiental na bacia do Rio das Pedras, Guarapuava - PR. 2004. 79 f. Dissertação (Mestrado) - Curso de Pósgraduação em Ciências do Solo, Setor de Ciências Agrárias, Universidade Federal do Paraná, Curitiba, 2004.

PACHECO, F. F. Análise Multicritério aplicada na seleção de áreas aptas a construção de barraginhas em relevo forte ondulado. 2016. 33 f. TCC (Graduação) - Curso de Graduação em Geografia, Departamento de Geografia, Universidade Federal de Viçosa, Viçosa, 2016.

PINTO, C. T. et al. Identificação de áreas susceptíveis a processos erosivos na região do Vale do Paraíba. In: XVII Simpósio Brasileiro de Sensoriamento Remoto, 17., 2015, João Pessoa. Anais... João Pessoa: SBSR, 2015. p. 67-74.

RIBEIRO, A. S. Vulnerabilidade ambiental da sub-bacia hidrográfica do rio Mandu, sul de Minas Gerais. 2014. 63 f. Dissertação (Mestrado) - Curso de Pós-graduação em Ecologia e Tecnologia Ambiental, Universidade Federal de Alfenas, Alfenas, 2014.

SANTOS, A. R.; LOUZADA, F. L. R. O.; EUGÊNIO, F. C. ArcGIS 9.3 Total: Aplicações para Dados Espaciais. Alegre: CAUFES, 2010. 184 p.

VERSIANI JÚNIOR, E. R.; NUZZI, G. A. R.; FRÓES, A. R. Projeto de Revitalização da Microbacia do Rio Abóboras - Bacia Hidrográfica São Lamberto. In: SIMPÓSIO BRASILEIRO DE CAPTAÇÃO E MANEJO DE ÁGUA DE CHUVA, 6., 2007, Belo Horizonte. Anais... . Belo Horizonte: ABCMAC, 2007. 